\title{
Acceptability and Factors Associated with Immediate Postpartum Intrauterine Contraceptive Device Use Among Women Who Gave Birth at Government Hospitals of Gamo Zone, Southern Ethiopia, 2019
}

This article was published in the following Dove Press journal:

Open Access Journal of Contraception

\begin{abstract}
Mesfin Gebremedhin Jnr (iD) Addisu Alemayehu (D) ${ }^{2}$ Manaye Yihune (D) Samuel Dessu iD ${ }^{3}$

Tamirat Melis ${ }^{4}$ Negash Nurahmed (iD ${ }^{5}$

'Arba Minch University, College of Medicine \& Health Sciences, Department of Public Health, Arba Minch, Ethiopia; ${ }^{2}$ Dilla University, College of Medicine \& Health Sciences, Department of Public Health, Dilla, Ethiopia; ${ }^{3}$ Wolkite University, College of Medicine \& Health Sciences, Department of Public Health, Wolkite, Ethiopia; ${ }^{4}$ Wachamo University, College of Medicine \& Health Sciences, Department of Public Health, Hosanna, Ethiopia; ${ }^{5}$ Paster Ethiopian Public Health Institute, Addis Ababa, Ethiopia
\end{abstract}

Correspondence: Mesfin Gebremedhin Jnr Email mesfing762@gmail.com
Background: An intrauterine contraceptive device is suitable for women of all reproductive age groups for preventing unwanted pregnancies. Immediate postpartum family planning (PPFP) services need to be emphasized when the woman leaves the hospital. Despite the accepted demand for PPFP, many women do not access the services. Therefore, this study aimed to assess acceptability and factors associated with immediate postpartum intrauterine contraceptive device use among women who gave birth at government hospitals of Gamo Zone, Southern Ethiopia.

Methods: A cross-sectional study was conducted from March 1 to 30, 2019 with 452 participants studied using systematic random sampling technique. Data was collected using a pretested interviewer-administered questionnaire from March 1 to 30, 2019. The data were coded, cleaned and entered into Epi-data manager version 4.2.2.1 and exported to SPSS version 23 for advanced analysis. Binary logistic regression was performed to identify associated factors of immediate PPIUCD acceptability.

Results: This study revealed that about $161(35.6 \%)$ in $95 \%$ CI $(31.0,39.6)$ of the study participants accepted immediate PPIUCD. Multiparty (AOR $=2.33,95 \%$ CI, $(1.29,4.20)$ ), completed antenatal follow up $(\mathrm{AOR}=3.65,95 \% \mathrm{CI},(2.22,5.99))$, counselling $(\mathrm{AOR}=8.38$, 95\% CI, $(4.85,14.48)$ ) and prior discussion $(\mathrm{AOR}=2.57,95 \% \mathrm{CI},(1.51,4.36))$ were statistically significant.

Conclusion and Recommendation: Even though 58\% of the mothers were counselled about PPIUCD during the important cascade of pregnancy and 53\% of the mothers completed antenatal service, efforts need to improve antenatal care services and integrate counselling services through the whole cascade of pregnancy.

Keywords: acceptability, immediate postpartum intrauterine contraceptive device

\section{Background}

The intrauterine contraceptive device (IUCD) is a small plastic device that is inserted into the uterus and one of the long-term reversible family planning method choices. It is suitable for women of all reproductive ages, and represents the most cost effective contraceptive method for preventing unwanted pregnancies. Provision of IUCD during the immediate postpartum period is an effective and safe method for spacing and limiting births because it gives the advantage of the immediate postpartum period for counselling on family planning method choices. ${ }^{1,2}$ 
Postpartum period is one of the critical times when both woman and newborn need a special and integrated package of health services as morbidity and mortality rates are quite high during this period and also the women are vulnerable to unintended pregnancy. It is an ideal time to educate about future fertility and provision of appropriate family planning (FP) methods like IUCD. ${ }^{3}$

Intrauterine contraceptive device use is particularly important in sub-Saharan African countries, because there is a large unmet need for long acting and permanent methods during the postpartum period. Moreover, in developing countries, women who go back home after delivery do not return for even a routine postpartum check-up, leave aside contraception. Thus, immediate postpartum contraceptive services need to be emphasized where in the woman leaves the hospital with an effective contraception in place. ${ }^{4,5}$ Most women do not desire a pregnancy immediately after delivery but are unclear about contraceptive usage in the postpartum period. ${ }^{12}$

According to mini Ethiopia demographic health survey 2014, reports showed that IUCD use has been nearly absent from the contraceptive method mix. It showed that from $28.8 \%$ modern FP method choices, the use of IUCD contributed only $0.8 \%$. The report also implied that there was almost no focus on immediate postpartum IUCD use. ${ }^{6}$

The Health Sector Transformation Programme 2015-2020 has focused on equitable service but the core equity indicators of this document did not include FP indicators, no details about long acting family planning methods, but the revised reproductive health strategy gives due emphasis to focuses on long acting FP methods by setting clear targets, to increase the proportion IUCD to $7 \%$ and meet the need for immediate postpartum contraception to $100 \%$ by $2020,{ }^{7,8}$ since in Ethiopia there is a scarcity of information and evidence on immediate postpartum IUCD acceptance.

Findings from this study will contribute to the benefit of society, planners to designing strategies so as to promote the use of postpartum IUCD and researchers who will be interested to study this and related topics by providing a base line information.

\section{Methods}

\section{Study Setting and Design}

The study was conducted in government hospitals of Gamo zone, Southern Ethiopia which has being given immediate postpartum IUCD service. Arba Minch town is the capital city of Gamo zone which is $505 \mathrm{~km}$ southwest from Addis Ababa, the capital city of Ethiopia. The town has elevation of 1285 meters above sea level. All of the hospitals have been given maternal and child health services like skilled delivery and family planning.

\section{Sample Size and Sampling Procedure}

The sample size was determined using epi-info-v.7.2.2.6 calculator. Then the sample was taken as 422 by considering the following assumptions; confidence interval of $95 \%$, power of $80 \%$, ratio of unexposed to exposed group equal to one, outcome or proportion in unexposed group and adjusted odds ratio of parity was considered. ${ }^{9}$ After adding $10 \%$ non-response rate, the final sample size was calculated as 465 .

All the three government hospitals that provide immediate postpartum intrauterine device (IPPIUCD) services were included in the study. The total sample size was allocated to each hospital proportional to size ratio allocation based on monthly skilled delivery services. Systematic random sampling technique was used to select study subjects using delivery registration book who were eligible for immediate PPIUCD use. The first respondent from each hospital was selected randomly by lottery method.

\section{Eligibility Criteria Inclusion Criteria}

All postnatal women who gave birth at Gamo zone hospitals, southern Ethiopia, during the study period were included.

\section{Exclusion Criteria}

Postnatal women who did not fulfill world health organization (WHO) medical eligibility criteria (MEC) for intrauterine contraceptive device insertion were excluded (66). Women who were critically ill patients during data collection period. Women who could not communicate.

\section{Data Collection Instrument and Procedure}

The data were collected by using a semi-structured, translated and pre-tested questionnaire. The pretest was done at Lante health center, Gamo zone, Southern Ethiopia that provides immediate PPIUCD. It was done on about $5 \%$ of the sample to check consistency of the questionnaire before conducting the major study. Data were collected by using interviewer administered semi-structured questionnaire which was developed from different literatures 
and it contains socio-demographic, individual related factors, reproductive health and family planning related factors and facility related factors. ${ }^{9-12}$

\section{Operational Definition}

Postpartum IUCD acceptance is defined as those women who gave verbal consent to use IUCD within 10 minutes to 48 hrs of delivery of placenta. ${ }^{10}$

Postpartum family planning counseling is defined as counselled about PPIUD during ANC or latent phase of labour or within $48 \mathrm{~h}$ of delivery if the health professionals told her at least either of the benefit, side effects or duration of PPIUD use. ${ }^{11}$

Immediate postpartum IUCD is one of the PPFP method choices which is inserted immediately following delivery of the placenta but within 48 hours of delivery. ${ }^{1}$

Knowledge of immediate postpartum IUCD was measured if respondent knows about postpartum IUCDs as family planning method. It was measured by calculating the mean score of 10 items and categorized as having a good knowledge (if the participant answered greater than the mean score of knowledgeable questions) or not having a good knowledge (if the participant scored less than mean score of knowledgeable questions). ${ }^{13}$

Attitude in immediate postpartum IUCD were measured in the following way. ${ }^{14}$ Favorable attitude: from seven attitude measuring questions, those who score above mean to the correct answers from attitude measuring questions. Unfavorable attitude: from seven attitude measuring questions, those participants who scored mean and below the mean to the correct answers. For the purpose of analysis, the attitude of women was grouped into agree and disagree.

\section{Data Processing and Analysis}

EpiData manager $\mathrm{v}$ 4.4.2.1 was used for data coding, cleaning and entry. After entry the data were exported to SPSS (statistical package for social science) v 23.0 software for analysis. Data were reported in the form of graphs, tables, charts and texts to show the results. A crosstab was computed to see the occurrence of events among exposed and non exposed groups. The bivariate analysis was done by fitting logistic regression for each explanatory variable separately with $95 \%$ CI to assess their crude effect on their outcome variable and statistical significance. Variables with $p$-values of $\leq 0.25$ in bivariate analysis were included in multivariate logistic regression model to identify independent significant associated factors. The strength of statistical association was measured by adjusted odds ratios, 95\% confidence intervals, and P-value $\leq 0.05$ was considered as significant. All the necessary assumptions for the application of multivariable logistic regression model were maintained. The fitness of the model test was checked by Hosmer and Lemeshow test, and omnibus test of model coefficients was also considered. Finally, odds ratio with $95 \%$ CI were used to show the degree of association between the independent variables and immediate postpartum IUCD acceptability.

\section{Result \\ Socio-Demographic Characteristics of Study Participants}

A total of 452 clients were included in the post service interview, making a response rate of $97.2 \%$. Of the study participants, $269(59.50 \%)$ were in the age range of 25-34 years. The mean age of participants was 27 (4.8 SD). Majority of the study participants, 168 (37.2\%), completed primary education (Table 1).

\section{Knowledge and Attitude of Study Participants Towards Immediate PPIUCD} During study period, the majority of study participants, $360(79.6 \%)(n=452)$, had heard about immediate PPIUCD through different sources of information. Majority of study participants, 249 (69.60\%), heard message through health workers, followed by (32\%) mass media in the last 12 months. About $69(15 \%)$ of the respondents heard both from mass media and health workers (Figure 1).

Among the respondents who had heard about immediate PPIUCD $(n=360)$, majority of the respondents, 210 (58\%), had good knowledge about immediate PPIUCD. Among the respondents who had heard about immediate PPIUCD $(n=360)$, more than half of the respondents, 195 (54\%), had negative attitude about immediate PPIUCD.

\section{Reproductive History and Use of Family Planning of the Study Participants}

From respondents $(n=452)$, the majority, $281(62.20 \%)$, were multipara and majority of the respondents, 274 (61.1\%), also had 1-2 children. From respondents, majority, 340 (75.20\%), had planned to have another child in the near future. Almost half of the respondents, $227(52.67 \%)$, had attended at least 4 visits in their current pregnancy. During study period, majority of 
Table I Socio-Demographic Characteristics of the Study Participants in Gamo Zone Hospitals, Southern Ethiopia, 2019

\begin{tabular}{|c|c|c|c|}
\hline Variables $(n=452)$ & Categories & Frequencies (n) & Percent (\%) \\
\hline \multirow[t]{3}{*}{ Age (completed years) } & $15-24$ & 140 & 31.0 \\
\hline & $25-34$ & 269 & 59.5 \\
\hline & $35-49$ & 43 & 9.5 \\
\hline \multirow[t]{4}{*}{ Educational status } & No formal education & 86 & 19.0 \\
\hline & Primary education & 168 & 37.2 \\
\hline & Secondary education & 124 & 27.4 \\
\hline & Above secondary education & 74 & 16.0 \\
\hline \multirow[t]{4}{*}{ Respondents husband educational status } & No formal education & 59 & 13.6 \\
\hline & Primary education & $|3|$ & 30.2 \\
\hline & Secondary education & 88 & 20.3 \\
\hline & Above secondary education & 156 & 35.9 \\
\hline \multirow[t]{3}{*}{ Marital status } & Married & 434 & 96.0 \\
\hline & Unmarried & 14 & 3.1 \\
\hline & Others & 4 & 0.9 \\
\hline \multirow[t]{5}{*}{ Ethnicity } & Gamo & 260 & 57.5 \\
\hline & Gofa & 54 & 11.9 \\
\hline & Konso & 73 & 16.2 \\
\hline & Wolayta & 45 & 10.0 \\
\hline & Others & 20 & 4.4 \\
\hline \multirow[t]{3}{*}{ Religion } & Orthodox Christian & 214 & 47.3 \\
\hline & Protestant Christian & 219 & 48.5 \\
\hline & Muslim & 19 & 4.2 \\
\hline \multirow[t]{2}{*}{ Occupational status } & Employed & 258 & 57.1 \\
\hline & Unemployed & 194 & 42.9 \\
\hline \multirow[t]{2}{*}{ Residence } & Rural & 188 & 41.6 \\
\hline & Urban & 264 & 58.4 \\
\hline
\end{tabular}

study participants, $372(82.3 \%)$, had used any FP before the current pregnancy and majority of them, 299 $(80.40 \%)$, had used injectables.

During study period, majority of study participants, 261 (57.7\%), were counselled about immediate PPIUCD. Among those counselled during the study period $(n=279)$, majority of them, $195(74.70 \%)$, were counselled within 48 hours of their delivery (Figure 2).

\section{Acceptance of Immediate Postpartum Intrauterine Device}

This study revealed that $161(35.6 \%)$ of the respondents had showed willingness to use immediate postpartum IUCD. From the study participants who were interested in using PPIUCD $(n=161)$, their main reason were using IUCD was prevents pregnancy for a long period of time, 106 (65.8\%) (Figure 3).

\section{Factors Associated with Acceptance of Immediate PPIUCD}

Bivariate analysis was performed to assess factors which were significantly associated with acceptance of immediate PPIUCD. In binary logistic regression analysis, seven variables were associated with immediate PPIUCD acceptance. These were participant's age, residence, previous family planning use, counseling, ANC follow-up completion status and prior discussion with partner about family planning. In multivariable logistic regression analysis, four variables were independently associated with immediate PPIUD acceptance. These were parity, counseling, prior discussion with partner about FP and ANC follow-up completion status.

Mothers who had delivered multiple times were 2.33 times more likely to accept immediate PPIUD than their counterparts $(\mathrm{AOR}=2.33,95 \% \mathrm{CI}: 2.33$ (1.29, 4.20)). 


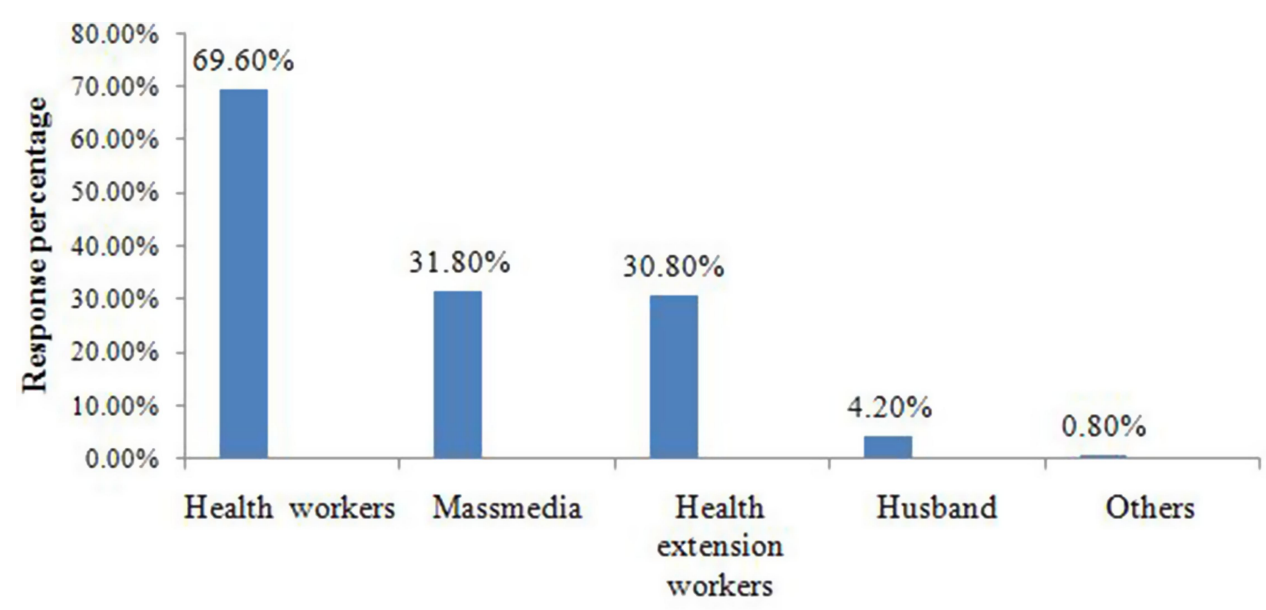

Source of information about immediate PPIUCD

Figure I Source of information about postpartum IUCD among postnatal women at Gamo zone hospitals, Southern Ethiopia, 2019.

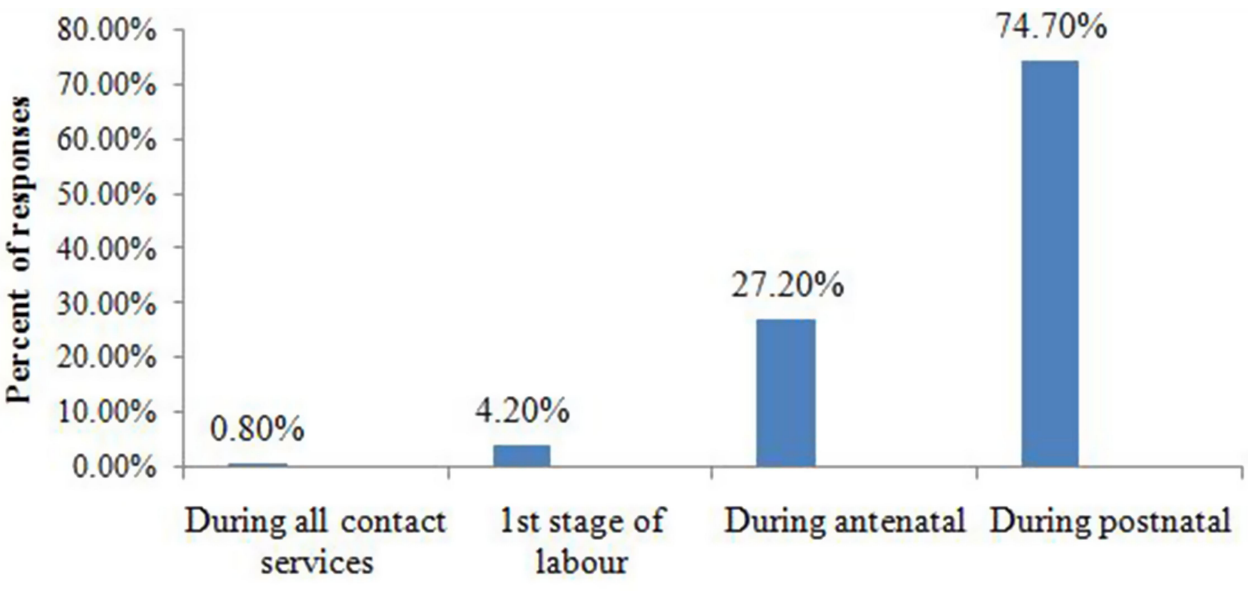

Timing of counselling about immediate PPIUCD

Figure 2 Distribution of timing of counselling among mothers who gave births at Gamo zone hospitals, South Ethiopia, 2019.

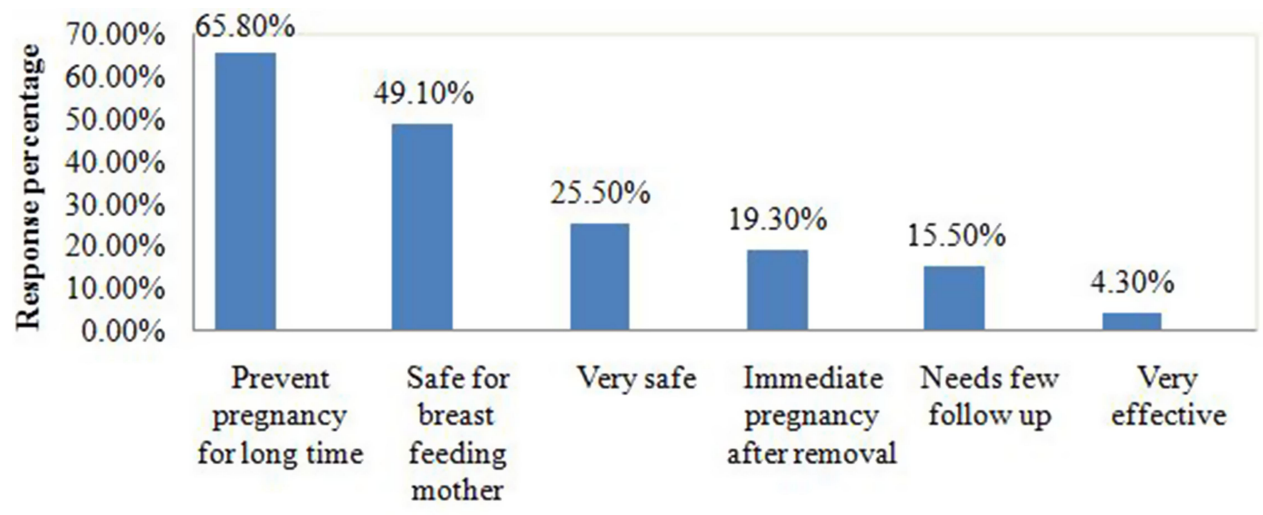

Reason for acceptance of immediate PPIUCD

Figure 3 The reasons for acceptance of immediate PPIUCD among delivered mothers in Gamo zone, Southern Ethiopia, 2019. 
Table 2 Adjusted Odds Ratio with 95\% Cl of Logistic Regression Showing Significant Association Factors on the Likelihood of Immediate PPIUCD Acceptance Among Study Participants in Gamo Zone Hospitals, Southern Ethiopia, 2019

\begin{tabular}{|c|c|c|c|c|c|}
\hline \multirow[t]{2}{*}{ Variables $(n=452)$} & \multirow[t]{2}{*}{ Categories } & \multicolumn{4}{|c|}{ Immediate PPIUCD Acceptance } \\
\hline & & Yes & No & COR $(95 \% \mathrm{Cl})$ & AOR (95\% CI) \\
\hline \multirow[t]{3}{*}{ Participant's age } & $35-49$ & 22 & 21 & $2.29(I .14,4.59)$ & $2.08(0.81,5.32)$ \\
\hline & $25-34$ & 95 & 174 & $1.19(0.77,1.84)$ & $0.76(0.4 \mathrm{I}, \mathrm{I} .37)$ \\
\hline & $15-24$ & 44 & 96 & 1 & 1 \\
\hline \multirow[t]{2}{*}{ Residence } & Urban & 103 & 161 & $1.43(0.96,2.13)$ & \\
\hline & Rural & 58 & 130 & 1 & \\
\hline \multirow[t]{2}{*}{ Parity } & Multipara & 115 & 166 & $1.88(1.25,2.85)$ & $2.33(1.29,4.20)^{*}$ \\
\hline & Primipara & 46 & 125 & I & I \\
\hline \multirow[t]{2}{*}{ Previous FP use } & Yes & 143 & 229 & $2.15(1.22,3.78)$ & \\
\hline & No & 18 & 62 & 1 & \\
\hline \multirow[t]{2}{*}{ Counseling } & Yes & 139 & 122 & $8.75(5.28, \mid 4.52)$ & $8.38(4.85,14.48)^{*}$ \\
\hline & No & 22 & 169 & 1 & I \\
\hline \multirow[t]{2}{*}{ ANC follow up completion status } & Yes & 106 & 121 & $2.37(1.58,3.56)$ & $3.65(2.22,5.99)^{*}$ \\
\hline & No & 55 & 149 & I & I \\
\hline \multirow[t]{2}{*}{ Prior discussion about FP } & Yes & 128 & 162 & I3.09 (I.98,4.83) & $2.57(\mathrm{I} .5 \mathrm{I}, 4.36)^{*}$ \\
\hline & No & 33 & 129 & I & 1 \\
\hline
\end{tabular}

Note: $*$ Significant in multivariate binary logistic regression at $\mathrm{p}$-value $=0.001$.

Mothers who had complete ANC follow up during current pregnancy were 3.65 times more likely to accept immediate PPIUD than mothers who did not complete ANC follow up (AOR=3.65, 95\% CI: $3.65(2.22,5.99)$ ).

Mothers who were counselled about immediate PPIUD were about 8.38 times more likely to accept immediate PPIUD than mothers who did not receive counseling service about immediate PPIUD (AOR $=8.38,95 \%$ CI: 8.38 $(4.85,14.48))$. Mothers who had discussed about family planning with their partner were 2.57 times more likely to accept immediate PPIUCD than those who had not discussed with their partner $(\mathrm{AOR}=2.57,95 \%$ CI $(1.57$, 4.36)) (Table 2).

\section{Discussion}

This study revealed that about $161(35.6 \%)$ in 95\% CI $(31.0,39.6)$ of the study participants accepted immediate PPIUCD. This result is still low compared with similar studies done in Sidama zone, southern Ethiopia and India. ${ }^{15-18}$ The possible explanation might be difference in culture and religion of the respondents for the Indian mothers. The other possible explanation might be difference in intervention by government and non government organization to improve postpartum FP including IUCD. ${ }^{1,19}$
Although this study is lower than studies done in India, it is higher than study done in Bale zone, western Ethiopia. ${ }^{10}$ The possible explanation might be in Gamo zone all study hospitals were supported by Engender health, Ethiopia, that may be improve women's awareness and attitude through different strategies.

This study showed that multipara women were more likely to accept immediate PPIUCD than their counterparts. Similar finding was reported by a study done across four countries: India, Nepal, and Sri Lanka; among Tanzanian women who had higher parity were more likely to accept immediate PPIUCD than their counterparts. ${ }^{20}$ The possible explanation might be multipara women needs optimal inter births gap between the current and previous births, therefore, these suggested that multipara women would likely accept safe and effective immediate postpartum family planning like PPIUCD. ${ }^{21}$ Inconsistent findings were reported by the same study done across four countries: India, Nepal, Sri Lanka, and Tanzania; showed that among delivered women who had higher parity were less likely to accept immediate PPIUCD than the counterparts for Indian and Sri Lankan women.

Another study done in India showed that primipara mothers showed more willingness to immediate PPIUCD use than their counterparts. ${ }^{15,20}$ The possible explanation 
might be the willingness to use immediate PPIUCD in multipara women was comparatively low due to the needs for permanent method in women who had two and more children.

In this study, mothers who had complete ANC follow up during current pregnancy were more likely to accept immediate PPIUCD than mothers who did not complete ANC follow up. Among the respondents, about 277 (53\%) of them had attended at least four or more ANC visits in their current pregnancy. Similar findings were reported in Indian women who attended ANC visits played a significant role in the acceptance of PPIUCD use. A study done in Bale zone, western Ethiopia showed that the odds of accepting immediate PPIUCD use was higher among women who attended three ANC visits than those who did not attend ANC visits for their current birth. ${ }^{10,17}$ The possible explanation might be completing ANC visits give the chance for health providers to give education on immediate postpartum FP method choices multiple times and clarified misconceptions about immediate PPIUCD resulting in willingness to adopt PPIUCD.

In this study, mothers who were counselled about immediate PPIUD were more likely to accept immediate PPIUD than mothers who did not receive counseling. Similar findings were reported by a study done across four countries data (India, Nepal, Sri Lanka, and Tanzania) showed that among delivered women who had counselled were more likely to accept immediate PPIUD than their counterparts. ${ }^{20}$ The possible explanation might be counselling about PPIUCD could make women to initiate their interest by clarified misconceptions about immediate PPIUCD.

In this study, women who had discussed with their partner about FP were more likely show willingness to use immediate PPIUCD than those who had not discussed with their partner about FP. This finding is supported by studies done in India, which showed those who had exposure to prior discussion with their partner could increase the likelihood of acceptance of PPIUCD. ${ }^{22}$ The possible explanation might be women who had prior discussion to their husband improve their decision making power to choose confidently the possible family planning choices. The other possible explanation might be partners who make discussion about FP gives the chance to increase awareness about PPIUCD each other. Finally this variable is only significant in this study, so it needs further test.

\section{Limitation of the Study}

Because this study was done at facility level it lacks generalization to women who delivered at home. The data given from the respondents was all self reported.

\section{Conclusion}

This finding revealed that about $161(36 \%)$ of the respondents showed willingness to use immediate PPIUCD. Although the majority of the study participants, 261 (58\%), were counseled about immediate PPIUCD, only less than one percent, 2 $(0.8 \%)$, of mothers were counselled during in all important contact points through the whole cascade of pregnancy. In this study, about 431 (95.4\%) of the study participants had attended at least one ANC visit(s), but about 227 (53\%) of the respondents had completed at least four ANC visits.

In this study parity, counseling, prior discussion with partner about family planning and ANC follow-up completion status were factors that positively predict the acceptability of immediate PPIUCD use. Therefore, increased efforts are needed from stakeholders and health service providers to promote counselling on immediate PPIUCD during the whole cascade of pregnancy (ANC, Delivery, and PNC).

\section{Abbreviations}

AOR, Adjusted Odds Ratio; ANC, Antenatal Care; CI, confident interval; PNC, Postnatal Care; PPIUCD, Postpartum Intrauterine Contraceptive Device; SPSS, Statistical Package for Social Science; WHO, World Health Organization.

\section{Data Sharing Statement}

Full data set and other materials relating to this study can be obtained from the corresponding authors upon reasonable request.

\section{Ethical Approval and Consent to Participate}

Ethics approval was obtained from the Institutional Research Ethics Review Board (IRB) Office, College of Medicine and Health Sciences Arba Minch University. Following the approval, official letter of cooperation from zonal health department was obtained to conduct the study in the three Hospitals providing postpartum IUCD. Data were collected after taking verbal consent according to the declaration of Helsinki from each participant. Purpose of study was explained and confidentiality was assured. Mothers whose age was less than 18 were considered to be early mature and 
gave oral informed consent. This is acceptable by Institutional Research Ethics Board (IRB) Office of Arba Minch University.

\section{Acknowledgment}

First, we would like to express our greatest gratitude to Almighty God whose blessing enabled us to all. We acknowledge gratefully all our data collectors for their commitment during data collection and all the service providers and managers in respective hospitals for giving us data which related to our research proposal. We would like to thank all clients who participated in the study scarifying their valuable time and information. Finally we would like to express our thanks to Arba Minch University, College of Medicine and Health Sciences, Department of Public Health for giving us this chance and support to prepare this research thesis.

\section{Author Contributions}

All authors made a significant contribution to the work reported, whether that is in the conception, study design, execution, acquisition of data, analysis and interpretation, or in all these areas; took part in drafting, revising or critically reviewing the article; gave final approval of the version to be published; have agreed on the journal to which the article has been submitted; and agree to be accountable for all aspects of the work.

\section{Disclosure}

The authors declare that they have no competing interests.

\section{References}

1. Family Planning Division Ministry of Health and Family Welfare Government of India. Postpartum IUCD reference manual Nirman Bhawan, New Delhi: Ministry of Health \& Family WelfareGovernmentofIndia; 2010. Available from:https://nhm.gov.in/ immages/pdf/guidelines/nrhm-guidelines/family-planning/medical-officer. pdf.

2. Cwiak C, Cordes S. Postpartum intrauterine device placement: a patient-friendly option. Contracept Reprod Med. 2018;3(1):3. doi:10.1186/s40834-018-0057-x

3. American College of Obstetricians and Gynecologists, Committee on Obstetric Practice. Committee opinion No. 670: immediate postpartum long-acting reversible contraception. Obstet Gynecol. 2016;128(2): e32-e37.

4. NATIONS U. United Nation: the Millennium development goals report. 2012.

5. Janwadkar A, Shekhawat GS. Acceptance, perception, experience and satisfaction of the couple with postpartum intrauterine contraceptive devices (PPIUCD) insertions. Asian Pac J Health Sci. 2016;3(4):55-64. doi:10.21276/apjhs.2016.3.4.9
6. CSA E. Mini Ethiopia demography health survey. 2014.

7. FMoH E. FMoH, the National reproductive health strategy for Ethiopia. 2016.

8. FMoH E. Federal democratic Republic of Ethiopia and Ministry of Health (MoH). Health Sector Transformation Plan; 2015.

9. Mbuthia FW, Okumbe GM, Monda J, Ng'ang'a PM. Intrauterine device uptake among women seeking family planning services in Nairobi County, Kenya. Afr J Midwifery Womens Health. 2017;11 (1):46-50. doi:10.12968/ajmw.2017.11.1.46

10. Gonie A, Worku C, Assefa T, Bogale D, Girma A. Acceptability and factors associated with post-partum IUCD use among women who gave birth at bale zone health facilities, Southeast-Ethiopia. Contracept Reprod Med. 2018;3(1):16. doi:10.1186/s40834-0180071-z

11. Tefera L, Abera M, Fikru C, Tesfaye D. Utilization of immediate post-partum intra uterine contraceptive device and associated factors: a facility based cross sectional study among mothers delivered at public health facilities of Sidama Zone, South Ethiopia. J Preg Child Health. 2017;4(3):1000326. one quarter. 2017;121(39):16-24. ISSN: 2376-127X. doi: 10.4172/2376-127X

12. Eluwa GI, Atamewalen R, Odogwu K, Ahonsi B. Success providing postpartum intrauterine devices in private-sector health care facilities in Nigeria: factors associated with uptake. Glob Health Sci Pract. 2016;4(2):276-283.

13. Kaydor VK, Adeoye IA, Olowolafe TA, Adekunle AO. Barriers to acceptance of post-partum family planning among women in Montserrado County, Liberia. Niger Postgrad Med J. 2018;25 (3):143. doi:10.4103/npmj.npmj_96_18

14. Gultie T, Hailu D, Workineh Y. Predictors of long acting contraceptives utilization among reproductive age women in Arba Minch Zuria district, Ethiopia. Qual Prim Care. 2016;24(1):17-22.

15. Nadu T A cross sectional study on willingness and acceptabily: PPIUCD by primipara mothers at a tertiary care hospital. 2017.

16. Agarwal N, Gupta M, Sharma A, Arora R. Antenatal counselling as a tool to increase acceptability of postpartum intrauterine contraceptive device insertion in a tertiary care hospital. Int $J$ Reprod Contracept Obstet Gynecol. 2015;4(4):1137-1141. doi:10.18203/ 2320-1770.ijrcog20150442

17. Kanmani K, Gokulakrishnan G, Rani PR. Acceptance of postplacental intrauterine contraceptive device: recent increase in trend. Int J Reprod Contracept Obstet Gynecol. 2016;5:1341-1344.

18. Kanhere AV, Pateriya P, Jain M. Acceptability and feasibility of immediate postpartum IUCD insertion in a tertiary care centre in Central India. Int J Reprod Contracept Obstet Gynecol. 2017;4 (1):179-184.

19. Jeffery MS, Ruparlia RA, Tredwell S. Post -partum intrauterine contraceptive device: a reference manual for provider. 2010.

20. Makins A, Taghinejadi N, Sethi M, et al. Factors influencing the likelihood of acceptance of postpartum intrauterine devices across four countries: India, Nepal, Sri Lanka, and Tanzania. Int J Gynecol Obstet. 2018;143:13-19. doi:10.1002/ijgo.12599

21. Grundy E, Kravdal Ø. Do short birth intervals have long-term implications for parental health? Results from analyses of complete cohort Norwegian register data. J Epidemiol Community Health. 2014;68 (10):958-964. doi:10.1136/jech-2014-204191

22. Valliappan A, Dorairajan G, Chinnakali P. Postpartum intrauterine contraceptive device: knowledge and factors affecting acceptance among pregnant/parturient women attending a large tertiary health center in Puducherry, India. Int $J$ Adv Med Health Res. 2017;4:69. doi:10.4103/IJAMR.IJAMR_28_17 


\section{Publish your work in this journal}

Open Access Journal of Contraception is an international, peerreviewed, open access, online journal, publishing original research, reports, reviews and commentaries on all areas of contraception. In addition to clinical research, demographics and health-related aspects, the journal welcomes new findings in animal and preclinical studies relating to understanding the biological mechanisms and practical development of new contraceptive agents. The manuscript management system is completely online and includes a very quick and fair peer-review system. Visit http://www.dovepress.com/testimonials. php to read real quotes from published authors.

Submit your manuscript here: http://www.dovepress.com/open-access-journal-of-contraception-journal 